\title{
Matt Morgan: When bullet points miss the heart
}

\author{
Matt Morgan intensive care consultant \\ University Hospital of Wales
}

My phone screen flashes as another email arrives. A solid block of justified text, dense and impenetrable, fills the screen, and my heart sinks. Even though its content is valuable, it's hard work just moving my eyes around to read the letters. Yet the next email is different: short and concise, with three neat bullet points that hit the heart of the matter. I respond immediately and feel content.

I'm naturally drawn to simplifying complex matters, while I try to manage each day in the intensive care unit. This applies to the small things too, such as the emails I write and the ones I prefer to read. So, I should perhaps welcome the ordered nature of electronic health records-but I don't.

To me, a series of short codes is not sufficient to summarise a prolonged clinical encounter. I worry that turning a month of complex illness and the resulting turmoil into a single line- "multiorgan failure owing to E coli sepsis"-loses something important. This summary is necessary, but it's not enough for patients, for healthcare staff, or for medical science. The electronic health record needs to capture not just the medical facts but a patient's narrative.

The evolution of electronic health records owes its existence to billing rather than communication. Precise and timely coding allows private healthcare providers to capture the dollars as well as the disease. It's no wonder that, in a sea of transactions, we lose the human story.

When I type my daily ward round notes I'm careful to make sure that I provide enough context. Yes, I use bullet points to list problems and abbreviations for the endless array of fancy tests we order-but I always try to finish with a story. The start of my notes summarises the story so far. The end describes what I think will, may, or should happen over the course of the following week.

I tell the patients' stories, using science, using medicine, but also using humanity: after all, the medical ethics expert Edmund Pellegrino described medicine as "the most humane of sciences, the most scientific of the humanities." ${ }^{1}$ The final paragraph in a patient's notes should say more than the list that precedes it, not because of its factual content but because of the language that joins it together. Using bullet points alone may allow me to take aim, but this would miss the heart of the matter.

Unlike emails, which work best in a concise form, electronic health records need a compulsory box for free text, to be filled with a story we can all relate to. This will help us remember that we're dealing with a person, not just a patient.

The author thanks Peter Brindley for introducing him to the Pellegrino quote.

Matt Morgan is an honorary senior research fellow at Cardiff University, consultant in intensive care medicine and research and development lead in critical care at University Hospital of Wales, and an editor of BMJ OnExamination. His first book, Critical, was published in 2019

Competing interests: I have read and understood BMJ policy on declaration of interests and declare that I have no competing interests.

Provenance and peer review: Commissioned; not externally peer reviewed.

Fins JJ. Edmund D. Pellegrino, MD 1920-2013. Trans Am Clin Climatol Assoc 2015;126 https://www.ncbi.nlm.nih.gov/pmc/articles/PMC4530700/.26567400

Published by the BMJ Publishing Group Limited. For permission to use (where not already granted under a licence) please go to http://group.bmj.com/group/rights-licensing/ permissions 